\title{
Associations with Post-Consultation Health-Status in Primary Care Managed Acute Exacerbation of COPD
}

\author{
David Gillespie (D) ${ }^{1,2}$, Nick Francis $\mathbb{D}^{3}{ }^{3}$, Haroon Ahmed ${ }^{4}$, Kerenza Hood (iD) ${ }^{2}$, Carl Llor ${ }^{5}$, \\ Patrick White $\mathbb{D}^{6}$, Emma Thomas-Jones ${ }^{2}$, Helen Stanton ${ }^{2}$, Bernadette Sewell ${ }^{7}$, Rhiannon Phillips ${ }^{8}$, \\ Gurudutt Naik ${ }^{4}$, Hasse Melbye ${ }^{9}$, Rachel Lowe ${ }^{2}$, Nigel Kirby ${ }^{2}$, Ann Cochrane ${ }^{10}$, Janine Bates ${ }^{2}$, \\ Mohammed Fasihul Alam ', Christopher Butler (D)'
}

\begin{abstract}
'Nuffield Department of Primary Care Health Sciences, University of Oxford, Oxford, England, UK; ${ }^{2}$ Centre for Trials Research, School of Medicine, College of Biomedical \& Life Sciences, Cardiff University, Cardiff, Wales, UK; ${ }^{3}$ Primary Care, Population Sciences and Medical Education, University of Southampton, Southampton, England, UK; ${ }^{4}$ Division of Population Medicine, School of Medicine, Cardiff University, Cardiff, Wales, UK; ${ }^{5}$ University Institute in Primary Care Research Jordi Gol, Via Roma Health Centre, Barcelona, Spain; ${ }^{6}$ School of Population Health and Environmental Sciences, Kings College London, London, England, UK; ${ }^{7}$ Swansea Centre for Health Economics, Swansea University, Swansea, Wales, UK; ${ }^{8}$ Cardiff School of Sport \& Health Science, Cardiff Metropolitan University, Cardiff, Wales, UK; ${ }^{9}$ General Practice Research Unit, Department of Community Medicine, UIT the Arctic University of Norway, Tromsø, Norway; ${ }^{10}$ York Trials Unit, Department of Health Sciences, University of York, York, England, UK;

I'Department of Public Health, College of Health Sciences, QU-Health, Qatar University, Doha, Qatar
\end{abstract}

Correspondence: David Gillespie, Nuffield Department of Primary Care Health Sciences, University of Oxford, Radcliffe Observatory Quarter, Woodstock Road, Oxford, England, OX2 6GG, UK, Email david.gillespie@phc.ox.ac.uk

Background: It has been demonstrated that antibiotic prescribing for Acute Exacerbations of Chronic Obstructive Pulmonary Disease (AECOPD) can be safely reduced in primary care when general practitioners have access to C-reactive protein (CRP) rapid testing.

Aim: To investigate the factors associated with post-consultation COPD health status in patients presenting with AECOPD in this setting.

Design and Setting: A cohort study of patients enrolled in a randomised controlled trial. Patients aged 40+ years with a clinical diagnosis of COPD who presented in primary care across England and Wales with an AECOPD were included.

Methods: Participants were contacted for follow-up at one- and two-weeks by phone and attended the practice four weeks after the index consultation. The outcome of interest was the Clinical COPD Questionnaire (CCQ) score. Multivariable multilevel linear regression models fitted to examine the factors associated with COPD health status in the four-weeks following consultation for an AECOPD.

Results: A total of 649 patients were included, with 1947 CCQ total scores analysed. Post-consultation CCQ total scores were significantly higher (worse) in participants with diabetes (adjusted mean difference $[\mathrm{AMD}]=0.26$; $95 \%$ confidence interval (CI) $0.08-$ 0.45 ), obese patients compared to those with normal body mass index (AMD $=0.25,95 \%$ CI $0.07-0.43$ ), and those who were prescribed oral antibiotics in the prior 12 months $(\mathrm{AMD}=0.26 ; 95 \% \mathrm{CI} 0.11-0.41)$, but only the two latter associations remained after adjusting for other sociodemographic variables.

Conclusion: COPD health status was worse in the four weeks following primary care consultation for AECOPD in patients with obesity and those prescribed oral antibiotics in the preceding year.

Keywords: chronic obstructive, health status, Primary Health Care, pulmonary disease, symptom exacerbation

\section{How This Fits in}

There are little data on changes in health status during an exacerbation in patients managed in primary care. We analysed data from patients presenting to primary care with an acute exacerbation of COPD to describe changes in health status over the course of a primary care managed exacerbation, and identify sociodemographic, and clinical factors associated with postconsultation health status. COPD health status was worse in the four weeks following primary care consultation for AECOPD 
in obese patients and those prescribed oral antibiotics in the preceding year. Current clinical management strategies for AECOPD, including the prescribing of antibiotics and oral corticosteroids, require closer examination for patients with a high Body Mass Index (BMI) or who have previously used antibiotics.

\section{Introduction}

Chronic Obstructive Pulmonary Disease (COPD) is a leading cause of global morbidity and mortality, accounting for an estimated 81.6 million disability adjusted life-years and 3.2 million deaths in $2019 .{ }^{1,2}$ It is the third leading cause of death in the UK and a major cause of emergency hospital admission, with an estimated annual cost to the NHS of $£ 1.9$ billion. ${ }^{3,4}$ Patients with COPD are prone to acute exacerbations where there is rapid and sustained worsening of symptoms beyond normal day-to-day variation. Exacerbations have a detrimental effect on patients' health status and quality of life..$^{5-8}$

Previous studies have found that health status and quality of life in patients with COPD are associated with in-hospital mortality for those who present with critical illness and with hospital re-admission. ${ }^{9,10}$ Changes in health status and quality of life during an acute exacerbation have mostly been investigated in hospitalised cohorts, with some evidence that an exacerbation leads to a serious deterioration in health status which improves during admission but deteriorates by 3 months post-discharge. Factors associated with health status in patients with COPD have been less well studied than other outcomes. Of 408 prognostic models for COPD outcomes, none used health status as an outcome (either as the sole outcome, nor as a component of a composite outcome), including those developed in an outpatient setting. ${ }^{11}$ Several studies of small, hospitalised cohorts found that co-morbid depressive symptoms, ${ }^{12}$ pre-admission exacerbation frequency, and severity of dyspnoea ${ }^{13}$ were associated with health status and quality of life scores.

There are little data on changes in health status during an exacerbation in patients managed in primary care. These data are needed given that more than $80 \%$ of acute exacerbations are managed in a primary care setting. ${ }^{14}$ Clinicians use a range of presenting features when determining whether or not to prescribe antibiotics in primary care, ${ }^{15}$ despite limited association with bacterial infection. ${ }^{16}$ Furthermore, it has been demonstrated that antibiotic use can safely be reduced in patients presenting with AECOPD in primary care using C-reactive Protein (CRP) guided prescribing. ${ }^{17}$

Understanding changes and determinants of health status in a primary care cohort of patients with AECOPD may help to identify factors that can be modified to improve health status during and after an exacerbation. We therefore analysed data from patients presenting to primary care with an AECOPD to describe changes in health status over the course of a primary care managed exacerbation, and identify sociodemographic, and clinical factors associated with health status.

\section{Method}

\section{Study Design}

This was a cohort study using data from an open, multi-site, parallel-group, individually randomised controlled trial (RCT) reported in line with STROBE guidelines. ${ }^{17-20}$ Participants were randomised 1:1 (using minimisation with a random component, minimised by the number of Anthonisen criteria present) to be managed according to usual care or usual care in addition to a CRP point-of-care test. Management decisions (including antibiotic prescribing) were recorded followed randomisation. Participants were contacted for follow-up by telephone at one- and two-weeks postconsultation and attended their primary care practice for a further follow-up four-weeks post-consultation. The trial outcomes were patient-reported use of antibiotics for acute exacerbations of COPD within 4 weeks after randomization and COPD-related health status at 2 weeks after randomization, as measured by the Clinical COPD Questionnaire, a 10item scale with scores ranging from 0 (very good COPD health status) to 6 (extremely poor COPD health status).

The trial randomised 653 participants. However, four withdrew consent for their data to be used. The analyses in this paper therefore use data from 649 participants, who together comprise a large cohort of patients presenting with an AECOPD to a primary care setting with sociodemographic, clinical history and presenting features data collected at the index consultation and COPD health status data collected at the index consultation and one-, two-, and four-weeks postconsultation. 
The protocol and findings for the original study are reported elsewhere ${ }^{17-19}$ Ethical approval for the original study was obtained in September 2014 (REC reference: 14/WA/1106). The aims of this paper fall within the remit of the original approvals for the trial. This study was conducted in accordance with the Declaration of Helsinki.

\section{Participants and Setting}

Participants were aged 40 years or older with a clinically recorded diagnosis of COPD (with or without spirometry confirmation) who presented to any of 86 General Practices across England and Wales between January 2015 and September 2017 with symptoms of an acute exacerbation for at least 1 to 21 days and had not initiated antibiotic therapy. Patients were ineligible if they were likely to have a concurrent infection at another site; had severe illness; if their GP felt that urgent referral to hospital was necessary; had past medical history of respiratory failure/mechanical ventilation; had an active inflammatory condition; had cystic fibrosis, tracheostomy, or bronchiectasis; were immunocompromised; or were currently pregnant. Full inclusion and exclusion criteria have been described previously. ${ }^{18}$

\section{Outcome}

The outcome of interest for the analyses reported in this paper was the Clinical COPD Questionnaire (CCQ) total score, a validated measure of COPD health status. This scale ranges from 0 to 6 (higher score $=$ worse COPD health status), and its items cover COPD symptoms, functional state, and mental state. It has an established minimal clinically important difference of $0.4 .^{21}$ We investigated associations between a range of sociodemographic and clinical variables with CCQ total scores measured at one-, two-, and four-weeks post-consultation.

Explanatory variables are outlined in Table 1.

\section{Statistical methods}

To investigate the association between the specified explanatory variables and COPD health status following consultation for AECOPD, multilevel linear regression models were fitted to CCQ scores, accounting for clustering of repeated CCQ observations within participants, and of participants within primary care practices (using an independent covariance structure and exponential residual variance-covariance structure for observations over time). All models adjusted for time point (1-week, 2-weeks, and 4-weeks), CCQ total score (ie at the point where patients presented with an acute exacerbation), antibiotic prescribing, and OCS prescribing at the index consultation, and allocation to usual care or CRPPOCT. Our modelling process involved first fitting explanatory variables individually, adjusting for clinical management decisions, and subsequently fitting multivariable models in a hierarchical fashion, with blocks of variables included in the following order (one block building on the other): 1 - sociodemographic; 2 - clinical history; 3 - presenting features; 4 -

Table I Explanatory Variables Studied

\begin{tabular}{|l|l|}
\hline Domain & Variables \\
\hline Sociodemographic variables & Age, sex, and Body Mass Index (BMI). \\
\hline Clinical history & $\begin{array}{r}\text { Heart failure, coronary heart disease, diabetes (either type I or II), chronic kidney disease } \\
\text { (CKD } 3 \text { or more), hypertension, smoking status (categorised as never smoked/ever smoked } \\
\text { for modelling purposes), percent predicted FEVI (a marker of COPD severity), and } \\
\text { whether the patient had been prescribed oral antibiotics for any reason in the I2 months } \\
\text { prior to their exacerbation. }\end{array}$ \\
\hline Presenting features of the acute exacerbation & $\begin{array}{r}\text { Season during which the consultation occurred, number of days with symptoms prior to } \\
\text { consulting, presence of increased breathlessness, increased sputum volume, increased } \\
\text { sputum purulence, sputum colour (estimated by the treating clinician if the patient was able } \\
\text { to produce sputum during the consultation, or graded by the patient if not, from I (least } \\
\left.\text { purulent) to } 5 \text { (most purulent) according to the BronkoTest }{ }^{\circledR}\right), \text { presence of chest sounds } \\
\text { (crackles, wheeze, diminished vesicular breathing), whether the patient was tachypnoeic, } \\
\text { body temperature, pulse rate, and oxygen saturation. }\end{array}$ \\
\hline
\end{tabular}


estimated sputum colour; 5 - presence of chest sounds; 6 - other clinical examinations. For each block, the marginal $\mathrm{r}^{2}$ was calculated to assess the proportion of variance explained by the fixed effects included in the model. ${ }^{22}$

Continuous variables were investigated for non-linearity using restricted cubic splines and multiple imputation was used to impute missing data in regression models (see Online Supplementary Material for further details).

Model estimates are presented as adjusted mean differences (AMD), which can be interpreted as the adjusted mean difference in CCQ total scores averaged across the three post-consultation time points. We also report $95 \%$ confidence intervals (CIs) and p-values. Statistical analyses were conducted using Stata/SE v16.1. ${ }^{23}$

\section{Results}

Our cohort included 649 people with COPD presenting to primary care with an acute exacerbation. Overall, 335/649 $(51.6 \%)$ were male, the mean age was 68.1 years $(\mathrm{SD}=9.42$ years), and 175/603 $(29.0 \%)$ had a BMI within the "healthy weight" category (Table 2).

\section{Change in CQC Total Scores Over the Course of an Exacerbation}

The mean CCQ total score at the index consultation was $3.2(\mathrm{SE}=0.07)$, with differences in scores at one-, two-, and four-weeks post-consultation, compared to the index consultation, of -0.5 ( $95 \% \mathrm{CI}$ : -0.6 to -0.4$),-0.6$ (95\% CI: -0.7 to -0.5 ), and -0.7 (95\% CI: -0.8 to -0.7$)$, respectively. These differences in scores are all greater the established MCID of 0.4 , and the biggest difference (improvement) was observed between the index consultation and one-week postconsultation (Figure 1).

From a potential 1947 CCQ total scores (three observations per person during the four-weeks post-consultation) for 649 people, we had data on 1689 scores for 615 people. Four hundred and ninety-three (76.0\%) participants had all 3 scores, 88 (13.6\%) had 2 scores, 34 (5.2\%) had 1 score, and 34 (5.2\%) had 0 scores. Furthermore, as indicated in Table 2, the number of participants with missing explanatory variables ranged from $\mathrm{n}=0$ (age, gender, chronic health conditions, number of days with symptoms, exacerbation features, crackles, wheeze) to $\mathrm{n}=90$ (percent predicted FEV1). All missing data were imputed and therefore all statistical models described below are based on 1947 observations within 649 participants within 86 practices.

\section{Associations with Post-Consultation COPD Health Status}

In an initial model including time point, CCQ total score at the index consultation, antibiotic prescribing, and OCS prescribing only, the marginal $\mathrm{r}^{2}$ value was 0.594 (ie $59.4 \%$ of the total variance in post-consultation CCQ total scores was explained by the fixed effects in the model). After adjusting for CCQ total score at the index consultation, CCQ total scores decreased over time (ie the COPD health status of participants improved over the four-weeks), were lower in those prescribed antibiotics at the index consultation ( $\mathrm{AMD}=-0.16,95 \% \mathrm{CI}:-0.31$ to $-0.01, \mathrm{p}=0.039)$, and were also lower in those allocated to the CRP-POCT arm ( $\mathrm{AMD}=-0.24,95 \% \mathrm{CI}:-0.38$ to $-0.09, \mathrm{p}=0.001)$. In this model, there was no evidence of an association between post-consultation CCQ total score and the prescribing of oral corticosteroids at the index consultation ( $\mathrm{AMD}=-0.06,95 \% \mathrm{CI}$ : -0.22 to $0.09, \mathrm{p}=0.426$ ).

Examining sociodemographic variables individually, CCQ total scores were higher (ie worse) on average over the four-weeks post-consultation in participants in the obese BMI range (AMD compared to those in the healthy BMI range $=0.25,95 \%$ CI: 0.07 to $0.43, p=0.006$ ). This association remained after adjusting for other sociodemographic variables, as well as other variables relation to clinical history and presenting features (Table 3, Supplementary Table 1A). The marginal $r^{2}$ for the multivariable model including sociodemographic variables was 0.621 , representing an absolute increase from the initial model of 0.027 and a relative increase of $4.5 \%$ (Table 4 ).

Examining clinical history variables individually, CCQ total scores were higher on average over the four-weeks postconsultation in participants with diabetes (AMD $=0.26,95 \% \mathrm{CI}$ : 0.08 to $0.45, \mathrm{p}=0.005$ ) and those who were prescribed antibiotics in the prior 12 months (AMD $=0.26,95 \% \mathrm{CI}$ : 0.11 to $0.41, \mathrm{p}=0.001$ ). The association between those prescribed oral antibiotics for any reason in the prior 12 months and CCQ total scores remained after adjusting for sociodemographic variables, clinical history, and presenting features, but the association between diabetes did not (Table 3, Supplementary Table 1A). The marginal $\mathrm{r}^{2}$ for the multivariable model including clinical history in addition 
Table 2 Characteristics of Participants at the Index Consultation

\begin{tabular}{|c|c|c|c|}
\hline \multicolumn{2}{|l|}{ Variable } & \multirow{2}{*}{$\begin{array}{r}\text { Frequency } \\
335\end{array}$} & \multirow{2}{*}{$\begin{array}{r}\% \\
51.6\end{array}$} \\
\hline Participant sex $(n=649)$ & Male & & \\
\hline & Female & 314 & 48.4 \\
\hline \multirow[t]{4}{*}{ Body Mass Index category $(n=603)$} & Underweight & 22 & 3.6 \\
\hline & Healthy weight & 175 & 29.0 \\
\hline & Overweight & 193 & 32.0 \\
\hline & Obese & 213 & 35.3 \\
\hline \multicolumn{2}{|l|}{ Heart failure $(n=649)$} & 31 & 4.8 \\
\hline \multicolumn{2}{|l|}{ Chronic heart disease $(n=649)$} & 114 & 17.6 \\
\hline \multicolumn{2}{|l|}{ Diabetes $(n=649)$} & 104 & 16.0 \\
\hline \multicolumn{2}{|l|}{ Chronic kidney disease $(n=649)$} & 59 & 9.1 \\
\hline \multicolumn{2}{|l|}{ Hypertension $(n=649)$} & 267 & $4 I . I$ \\
\hline \multirow[t]{2}{*}{ Smoking status $(n=560)$} & Never smoked & 42 & 7.5 \\
\hline & Ever smoked & 518 & 92.5 \\
\hline \multicolumn{2}{|c|}{$\begin{array}{l}\text { Patient has been prescribed oral antibiotics in the past } 12 \text { months for any } \\
\text { reason }(n=606)\end{array}$} & 403 & 66.5 \\
\hline \multirow[t]{4}{*}{ Season of presentation $(n=649)$} & Winter & 323 & 49.8 \\
\hline & Spring & 110 & 16.9 \\
\hline & Summer & 48 & 7.4 \\
\hline & Autumn & 168 & 25.9 \\
\hline \multirow{3}{*}{$\begin{array}{l}\text { Number of days with exacerbation } \\
\text { prior to consulting }(n=649)\end{array}$} & I to 6 days & 366 & 56.4 \\
\hline & 7 to 13 days & 166 & 25.6 \\
\hline & 14+ days & 117 & 18.0 \\
\hline \multicolumn{2}{|l|}{ Increased breathlessness $(n=649)$} & 583 & 89.8 \\
\hline \multicolumn{2}{|l|}{ Increase sputum volume $(n=649)$} & 464 & 71.5 \\
\hline \multicolumn{2}{|l|}{ Increased sputum purulence $(n=649)$} & 389 & 59.9 \\
\hline \multirow[t]{5}{*}{ Sputum colour $(n=577)$} & Sputum colour I & 135 & 23.4 \\
\hline & Sputum colour 2 & 126 & 21.8 \\
\hline & Sputum colour 3 & 136 & 23.6 \\
\hline & Sputum colour 4 & 140 & 24.3 \\
\hline & Sputum colour 5 & 40 & 6.9 \\
\hline \multicolumn{2}{|l|}{ Crackles $(n=649)$} & 320 & 49.3 \\
\hline \multicolumn{2}{|l|}{ Wheeze $(n=649)$} & 338 & 52.1 \\
\hline \multicolumn{2}{|l|}{ Diminished vesicular breathing $(n=647)$} & 153 & 23.6 \\
\hline
\end{tabular}


Table 2 (Continued).

\begin{tabular}{|l|r|r|r|}
\hline \multicolumn{2}{|l|}{ Variable } & Frequency & \% \\
\hline \multicolumn{2}{|l|}{ Patient is tachypnoeic $(\mathrm{n}=589)$} & 88 & 14.9 \\
\hline Oxygen saturation $(\mathrm{n}=646)$ & $\begin{array}{r}\text { Normal or moderately decreased } \\
(>92 \%)\end{array}$ & 577 & 89.3 \\
\cline { 2 - 4 } & Low (up to 92\%) & 69 & Mean \\
\hline Variable & 68.1 & 10.7 \\
\hline Age $(n=649)$ & 59.8 & SD \\
\hline Percent predicted FEVI $(n=559)$ & 9.42 \\
\hline Body Temperature $(n=648)$ & 36.7 & 20.04 \\
\hline Pulse rate $(n=648)$ & 81.6 & 0.49 \\
\hline
\end{tabular}

to sociodemographic features was 0.661 , representing an absolute increase from the previous model of 0.040 and a relative increase of $6.4 \%$.

After adjusting for sociodemographic variables, clinical history, and presenting features, there was evidence to suggest an association between an increase in body temperature and lower post-consultation CCQ total scores (AMD per one-degree increase in temperature $=-0.17,95 \% \mathrm{CI}:-0.30$ to -0.03$)$ and an increase in pulse rate and higher CCQ total scores (AMD per on bpm increase in pulse rate $=0.01,95 \%$ CI: 0.00 to 0.01 ) (Table 3, Supplementary Table 1B). As shown in Supplementary Figures 1 and 2 , the magnitude of this association across the range of recorded temperatures and pulse rates was small and the majority of participants had body temperatures and pulse rates within normal ranges.

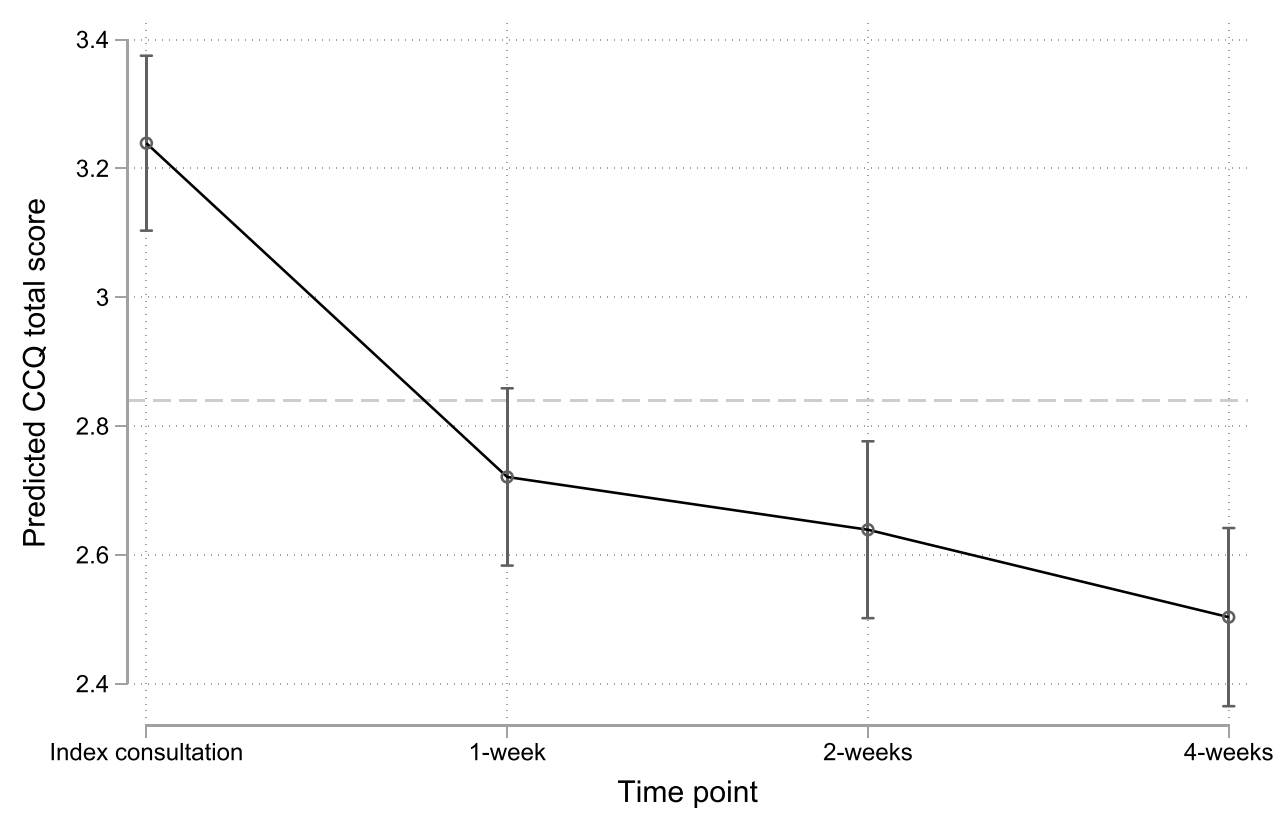

Figure I Predicted mean CCQ total scores over time (note full CCQ total score ranges from 0 to 6 )*. *Dashed line denotes a difference of 0.4 from the estimated mean CCQ total score at the index consultation. 
Table 3 Individual Associations Between Sociodemographic, Past Medical History, and Clinical Variables and Exacerbation Course in Patients with AECOPD in Primary Care*

\begin{tabular}{|c|c|c|c|c|c|c|}
\hline Domain & & Variable & AMD & $\begin{array}{r}\text { Lower } 95 \% \\
\mathrm{Cl}\end{array}$ & $\begin{array}{r}\text { Upper } 95 \% \\
\mathbf{C l}\end{array}$ & p-value \\
\hline \multirow[t]{7}{*}{ Sociodemographics } & \multicolumn{2}{|c|}{ Age (per decade increase) } & 0.02 & -0.06 & 0.09 & 0.688 \\
\hline & \multirow[t]{2}{*}{ Participant sex } & Male & \multicolumn{4}{|c|}{ Reference category } \\
\hline & & Female & -0.14 & -0.28 & 0.00 & 0.054 \\
\hline & \multirow[t]{4}{*}{ Body Mass Index category } & Underweight & 0.36 & -0.02 & 0.74 & 0.064 \\
\hline & & Healthy weight & \multicolumn{4}{|c|}{ Reference category } \\
\hline & & Overweight & 0.09 & -0.09 & 0.27 & 0.339 \\
\hline & & Obese & 0.25 & 0.07 & 0.43 & 0.006 \\
\hline \multirow{9}{*}{$\begin{array}{l}\text { Past medical } \\
\text { history }\end{array}$} & & Heart failure & 0.22 & -0.11 & 0.55 & 0.194 \\
\hline & & onic heart disease & 0.13 & -0.06 & 0.31 & 0.176 \\
\hline & & Diabetes & 0.26 & 0.08 & 0.45 & 0.005 \\
\hline & & nic kidney disease & 0.21 & -0.02 & 0.45 & 0.077 \\
\hline & & Hypertension & 0.11 & -0.04 & 0.25 & 0.142 \\
\hline & \multirow[t]{2}{*}{ Smoking status } & Never smoked & \multicolumn{4}{|c|}{ Reference category } \\
\hline & & Ever smoked & 0.13 & -0.16 & 0.42 & 0.371 \\
\hline & \multicolumn{2}{|c|}{$\begin{array}{l}\text { Patient has been prescribed oral antibiotics in the } \\
\text { past } 12 \text { months for any reason }\end{array}$} & 0.26 & 0.11 & $0.4 \mathrm{I}$ & 0.001 \\
\hline & \multicolumn{2}{|c|}{$\begin{array}{l}\text { Percent predicted FEVI } \\
\text { (per 10-point increase) }\end{array}$} & -0.03 & -0.06 & 0.00 & 0.160 \\
\hline \multirow{10}{*}{$\begin{array}{l}\text { Initial presenting } \\
\text { features }\end{array}$} & \multirow[t]{4}{*}{ Season of presentation } & Winter & \multicolumn{4}{|c|}{ Reference category } \\
\hline & & Spring & 0.00 & -0.20 & 0.21 & 0.980 \\
\hline & & Summer & -0.02 & -0.31 & 0.26 & 0.873 \\
\hline & & Autumn & -0.10 & -0.28 & 0.08 & 0.261 \\
\hline & \multirow{3}{*}{$\begin{array}{r}\text { Number of days with } \\
\text { exacerbation prior to } \\
\text { consulting }\end{array}$} & I to 6 days & \multicolumn{4}{|c|}{ Reference category } \\
\hline & & 7 to 13 days & -0.01 & -0.18 & 0.16 & 0.906 \\
\hline & & 14+ days & 0.08 & -0.11 & 0.27 & 0.423 \\
\hline & \multicolumn{2}{|c|}{ Increased breathlessness } & 0.07 & -0.17 & 0.32 & 0.558 \\
\hline & \multicolumn{2}{|c|}{ Increase sputum volume } & -0.01 & -0.17 & 0.14 & 0.869 \\
\hline & \multicolumn{2}{|c|}{ Increased sputum purulence } & 0.11 & -0.04 & 0.26 & 0.134 \\
\hline \multirow{5}{*}{$\begin{array}{l}\text { Estimated sputum } \\
\text { colour }\end{array}$} & \multirow[t]{5}{*}{ Sputum colour } & Sputum colour I & \multicolumn{4}{|c|}{ Reference category } \\
\hline & & Sputum colour 2 & -0.00 & -0.21 & 0.21 & 0.977 \\
\hline & & Sputum colour 3 & 0.14 & -0.08 & 0.35 & 0.212 \\
\hline & & Sputum colour 4 & 0.06 & -0.14 & 0.27 & 0.546 \\
\hline & & Sputum colour 5 & 0.16 & -0.15 & 0.48 & 0.313 \\
\hline
\end{tabular}


Table 3 (Continued).

\begin{tabular}{|c|c|c|c|c|c|c|}
\hline Domain & & Variable & AMD & $\begin{array}{r}\text { Lower 95\% } \\
\mathrm{CI}\end{array}$ & $\begin{array}{r}\text { Upper 95\% } \\
\text { Cl }\end{array}$ & p-value \\
\hline \multirow[t]{3}{*}{ Chest sounds } & & Crackles & -0.03 & -0.19 & 0.12 & 0.662 \\
\hline & & Wheeze & -0.08 & -0.24 & 0.07 & 0.302 \\
\hline & Diminis| & d vesicular breathing & -0.10 & -0.27 & 0.08 & 0.286 \\
\hline \multirow{5}{*}{$\begin{array}{l}\text { Other clinical } \\
\text { examinations }\end{array}$} & & atient is tachypnoeic & 0.11 & -0.11 & 0.34 & 0.322 \\
\hline & Body Temperature & per degree increase) & -0.13 & -0.27 & 0.01 & 0.078 \\
\hline & Pulse rate ( & ar one bpm increase) & 0.00 & -0.00 & 0.01 & 0.083 \\
\hline & Oxygen saturation & $\begin{array}{r}\text { Normal or } \\
\text { moderately } \\
\text { decreased }(>92 \%)\end{array}$ & \multicolumn{4}{|c|}{ Reference categor } \\
\hline & & Low (up to $92 \%$ ) & 0.14 & -0.10 & 0.37 & 0.260 \\
\hline
\end{tabular}

Notes: *All models correct for the clustered nature of repeated observations within individuals within practices (1947 observations within 649 individuals within 86 practices). Models adjust for time point (one-, two-, and four-weeks post-consultation), CCQ total score at the index consultation, trial arm (managed using a CRP point-ofcare test in addition to usual care or usual care alone), antibiotic prescribing, and oral corticosteroid prescribing at the index consultation.

Abbreviation: AMD, adjusted mean difference.

Table 4 Marginal $R^{2}$ Values Across Multivariable Models

\begin{tabular}{|l|r|r|r|r|}
\hline Block & Description & Marginal $\mathbf{R}^{2}$ & Absolute Difference & Relative Difference (\%) \\
\hline 0 & No explanatory variables* & 0.594 & N/A & 0.027 \\
\hline 1 & Sociodemographics & 0.621 & 0.04 & 4.5 \\
\hline 2 & Past medical history & 0.661 & 0.007 & 1.1 \\
\hline 3 & Initial presenting features & 0.668 & 0.003 & 0.4 \\
\hline 4 & Estimated sputum colour & 0.671 & 0.022 & 3.3 \\
\hline 5 & Presence of abnormal chest sounds & 0.693 & 0.025 & 3.6 \\
\hline 6 & Other clinical examinations & 0.718 & & \\
\hline
\end{tabular}

Notes: *Model included time point, CCQ total score at the index consultation, trial arm, antibiotic prescribing, and oral corticosteroid prescribing at the index consultation.

\section{Discussion}

\section{Summary of Key Findings}

We described health status in a cohort of patients presenting to primary care with an AECOPD and investigated variables associated with CQC total scores. Our findings suggest that COPD health status deteriorated over the four-week postconsultation period. COPD health status was worse for patients in the obese BMI category (compared to those in the healthy BMI category) and those prescribed oral antibiotics for any reason in the 12-months prior to their consultation. Our models indicated that patients with lower temperature at presentation or high pulse rate also had worse a COPD health status in the four-weeks post-consultation after adjusting for other explanatory variables. While we found an association between patients having diabetes and worse COPD health status post-consultation, no evidence of an association remained after adjusting for other variables. 


\section{Strengths and Limitations}

This analysis of a large cohort of patients used data from an RCT which was representative of individuals presenting in primary care with AECOPD across England and Wales. ${ }^{24,25}$ Repeated measurements of COPD health status allowed for an assessment of an individual's general COPD health status over this time rather than relying on a single measure to cover this entire. We accounted for key variables during the initial consultation which would likely confound any association between our explanatory variables and our outcome, specifically treatment with antibiotics and oral corticosteroids, including whether they were allocated to be managed with a CRP-POCT in addition to usual care or usual care alone, and their CCQ total score.

The study lacked a measure of CCQ total score during a stable period prior to the current exacerbation, meaning we were unable to measure "recovery from an exacerbation". The data for this analysis were obtained from an RCT, which was not designed to model the prognosis of patients with a COPD exacerbation. Implications of this are that our study may have omitted variables that are associated with COPD health status or recovery following a consultation for an exacerbation (eg clinical frailty measures, deprivation) and that the choice of health status outcome measure (ie the CCQ) was driven by considerations for the RCT rather than this particular investigation. While the CCQ has been validated for use and shown to be responsive in AECOPD populations, verification of these findings with other COPD-specific outcome measures (eg St. George's Respiratory Questionnaire, ${ }^{26}$ Chronic Respiratory Disease Questionnaire ${ }^{27}$ ) may be useful.

\section{Comparison with Existing Literature}

The association between BMI category and COPD health status following consultation for an AECOPD is in contrast to two studies which investigated exacerbation recovery and found no evidence of such an association. ${ }^{28,29}$ We found no evidence of an association between the season during which a patient consulted and COPD health status following consultation for an AECOPD nor between the number of days with an exacerbation prior to consulting and COPD health status post-consultation, in contrast to other studies. ${ }^{28,29}$ Previous work has similarly to our study found no evidence of an association between smoking status, age, sex, FEV1 percentage predicted, hypertension, and diabetes and recovery from COPD exacerbations. ${ }^{28,29}$ A prospective cohort study of patients with COPD recruited from an outpatient's clinic in the UK found longer exacerbation recovery times associated with increased dyspnoea and shorter recovery times associated with increased wheeze, whereas our study found no evidence suggestive of such an association. ${ }^{30}$ Divergent findings with regard to chest sounds may relate to inconsistencies in their interpretation..$^{31,32}$

\section{Implications}

Our findings suggest that, in those who have presented in primary care with an AECOPD, obese patients and those who were prescribed oral antibiotics in the prior 12-months for any reason have worse outcomes in terms of their COPD health status following their initial consultation for their exacerbation. These patients may be at increased risk of poor outcomes and also emphasise the role that weight reduction programmes may have on health outcomes in obese adults with COPD. ${ }^{33,34}$ The association between prior oral antibiotic prescription and poor outcomes may relate to the diverse nature of exacerbations $\mathrm{s}^{35}$ and warrant an investigation into the extent to which post-consultation outcomes are differentially associated with presenting and clinical variables by phenotype.

Further investigation may be needed to identify other key determinants of health status following an exacerbation, particularly those which may be modifiable via intervention. Further work is also needed to investigate the relationship between COPD health status and long-term COPD outcomes (eg hospitalisation, clinical deterioration, mortality) in those studied within the community.

\section{Conclusions}

BMI and a prior oral antibiotic prescription were both associated with a worse post-consultation health status in patients presenting in primary care with AECOPD. Current clinical management strategies for AECOPD, including the 
prescribing of antibiotics and oral corticosteroids, require closer examination for patients with a high BMI or who have previously used antibiotics.

\section{Data Sharing Statement}

Data will be made available upon request from researchers who provide a methodologically sound proposal, following assessment from the research team, and subject to a data sharing agreement. Data will be de-identified and will strictly adhere to patient confidentiality and consent. All relevant study protocols are on the NIHR project website. See: https://www.journalslibrary.nihr.ac.uk/programmes/hta/123312\#/.

\section{Ethics Approval}

Ethics approval for the original study was given on 15 September 2014 by the Research Ethics Committee (REC) for Wales (Wales REC 6), recognised by the United Kingdom Ethics Committee Authority (REC reference 14/WA/1106).

\section{Acknowledgments}

We would like to thank all patients who participated in the trials and their families, without whom this study would not have been possible. We would also like to acknowledge the contribution of other members of the original trial team (Angela Watkins, Miguel Cossio, Stephanie Robinson, Christy Barlow, Megan Philips-Laird, Deborah Fitzsimmons, and Micaela Gal. Margaret Barnard (who passed away in April 2016) and Jonathan Bidmead provided patient and public representation on the Trial Management Group. Jacqueline Nuttall provided study design input). Two UK Clinical Research Collaboration registered clinical trial units were involved in the study: Centre for Trials Research, Cardiff University; and University of Oxford Primary Care and Vaccines Clinical Trials Collaborative. We would also like to acknowledge and thank the Health \& Care Research Wales Workforce, the following CRNs for their support in helping to identify sites and carry out notes reviews at these sites: Thames Valley \& South Midlands CRN, East Midlands CRN, West Midlands CRN, West of England CRN, North Thames CRN, North West London CRN and South London CRN. We would like to express our thanks to Abbott Rapid Diagnostics, formally Alere Ltd, which provided the Afinion analysers and CRP cartridges and QC cartridges to the recruitment sites at no cost. Alere provided training on the use of the CRP POCT to a number of the participating sites.

The Centre for Trials Research is funded by Health \& Care Research Wales and Cancer Research UK.

\section{Author Contributions}

DG, CCB, and NAF originally conceived the idea for this paper. DG drafted the manuscript and conducted statistical analysis. Early drafts were reviewed by CCB, NAF, HA, and KH. All authors were involved in the design, acquisition, and interpretation of data for the paper. All authors made a significant contribution to the work reported, whether that is in the conception, study design, execution, acquisition of data, analysis and interpretation, or in all these areas; took part in drafting, revising or critically reviewing the article; gave final approval of the version to be published; have agreed on the journal to which the article has been submitted; and agree to be accountable for all aspects of the work.

\section{Funding}

The study was supported by funds from the NIHR Health Technology Assessment Programme (project number 12/33/12).

\section{Disclosure}

Authors DG, NF, HA, KH, PW, ET-J, BS, GN, RL, NK, JB, and CCB report grants from the National Institute for Health Research during the conduct of this study. NF also reports payments from Abbott for chairing and presenting at scientific meeting. CL reports grants from Abbott Diagnostics outside of the submitted work. RP reports grants from Health and Care Research Wales Research for Public and Patient Benefit, grants from Welsh Government/Ser Cymru, grants from Kidney Research UK and British Renal Society, grants from National Institute for Health Research Health Technology Assessment outside the submitted work. All other authors (HS, HM, AC, and MFA) report no potential competing interests. 


\section{References}

1. Dicker D, Nguyen G, Abate D, et al. Global, regional, and national age-sex-specific mortality and life expectancy, 1950-2017: a systematic analysis for the Global Burden of Disease Study 2017. Lancet. 2018;392(10159):1684-1735. doi:10.1016/S0140-6736(18)31891-9

2. Kyu HH, Abate D, Abate KH, et al. Global, regional, and national disability-adjusted life-years (DALYs) for 359 diseases and injuries and healthy life expectancy (HALE) for 195 countries and territories, 1990-2017: a systematic analysis for the Global Burden of Disease Study 2017. Lancet. 2018;392(10159):1859-1922. doi:10.1016/S0140-6736(18)32335-3

3. Steel N, Ford JA, Newton JN, et al. Changes in health in the countries of the UK and 150 English local authority areas 1990-2016: a systematic analysis for the Global Burden of Disease Study 2016. Lancet. 2018;392(10158):1647-1661. doi:10.1016/S0140-6736(18)32207-4

4. NHS England. Our ambition for respiratory disease [Internet]; [cited April 21, 2021]. Available from: https://www.england.nhs.uk/ourwork/clinicalpolicy/respiratory-disease/. Accessed January 27, 2022.

5. Aaron SD. Management and prevention of exacerbations of COPD. BMJ. 2014;349:g5237. doi:10.1136/bmj.g5237

6. Halpin DMG, Miravitlles M, Metzdorf N, Celli B. Impact and prevention of severe exacerbations of COPD: a review of the evidence. Int J COPD. 2017;12:2891-2908. doi:10.2147/COPD.S139470

7. Donaldson GC, Wedzicha JA. COPD exacerbations · 1: epidemiology. Thorax. 2006;61(2):164-168. doi:10.1136/thx.2005.041806

8. Anzueto A, Leimer I, Kesten S. Impact of frequency of COPD exacerbations on pulmonary function, health status and clinical outcomes. Int J Chron Obstruct Pulmon Dis. 2009;4:245-251.

9. Steer J, Gibson GJ, Bourke SC. Predicting outcomes following hospitalization for acute exacerbations of COPD. QJM. 2010;103(11):817-829. doi:10.1093/qjmed/hcq126

10. Rivera-Fernández R, Navarrete-Navarro P, Fernández-Mondejar E, Rodriguez-Elvira M, Guerrero-López F, Vázquez-Mata G. Six-year mortality and quality of life in critically ill patients with chronic obstructive pulmonary disease. Crit Care Med. 2006;34(9):2317-2324. doi:10.1097/01. CCM.0000233859.01815.38

11. Bellou V, Belbasis L, Konstantinidis AK, Tzoulaki I, Evangelou E. Prognostic models for outcome prediction in patients with chronic obstructive pulmonary disease: systematic review and critical appraisal. BMJ. 2019;367:15358. doi:10.1136/bmj.15358

12. Ng T-P, Niti M, Tan W-C, Cao Z, Ong KC. Depressive symptoms and chronic obstructive pulmonary disease: effect on mortality, hospital readmission, symptom burden, functional status, and quality of life. Arch Intern Med. 2007;167(1):60-67. doi:10.1001/archinte.167.1.60

13. Wang Q, Bourbeau J. Outcomes and health-related quality of life following hospitalization for an acute exacerbation of COPD. Respirology. 2005;10(3):334-340. doi:10.1111/j.1440-1843.2005.00718.x

14. GOLD. Global initiative for chronic obstructive lung disease: pocket guide to COPD diagnosis, management, and prevention, a guide for health care professionals. GOLD. 2017;2017.

15. Gillespie D, Butler CC, Bates J, et al. Associations with antibiotic prescribing for acute exacerbation of COPD in primary care: secondary analysis of a randomised controlled trial. Br J Gen Pract. 2021;71(705):e266LP-e272. doi:10.3399/BJGP.2020.0823

16. Francis NA, Gillespie D, Wootton M, et al. Clinical features and c-reactive protein as predictors of bacterial exacerbations of COPD. Int J Chron Obstruct Pulmon Dis. 2020;15:3147-3158. doi:10.2147/COPD.S265674

17. Butler CC, Gillespie D, White P, et al. C-reactive protein testing to guide antibiotic prescribing for COPD exacerbations. $N$ Engl J Med. 2019;381 (2):111-120. doi:10.1056/NEJMoa1803185

18. Bates J, Francis NA, White P, et al. General practitioner use of a C-reactive protein point-of-care test to help target antibiotic prescribing in patients with acute exacerbations of chronic obstructive pulmonary disease (the PACE study): study protocol for a randomised controlled trial. Trials. 2017;18(1):442. doi:10.1186/s13063-017-2144-8

19. Francis NA, Gillespie D, White P, et al. C-reactive protein point-of-care testing for safely reducing antibiotics for acute exacerbations of chronic obstructive pulmonary disease: the PACE RCT. Health Technol Assess. 2020;24(15): 1-108.

20. von Elm E, Altman DG, Egger M, Pocock SJ, Gøtzsche PC, Vandenbroucke JP. The Strengthening the Reporting of Observational Studies in Epidemiology (STROBE) Statement: guidelines for reporting observational studies. Int J Surg. 2014;12(12):1495-1499. doi:10.1016/j. ijsu.2014.07.013.

21. Zhou Z, Zhou A, Zhao Y, Chen P. Evaluating the clinical COPD questionnaire: a systematic review. Respirology. 2017;22(2):251-262. doi:10.1111/ resp. 12970

22. Nakagawa S, Schielzeth H. A general and simple method for obtaining R2 from generalized linear mixed-effects models. Methods Ecol Evol. 2013;4(2):133-142. doi:10.1111/j.2041-210x.2012.00261.x

23. StataCorp. Stata Statistical Software: Release 16. College Station, TX: StataCorp LLC; 2019.

24. Khan A, Dickens AP, Adab P, Jordan RE. Self-management behaviour and support among primary care COPD patients: cross-sectional analysis of data from the Birmingham Chronic Obstructive Pulmonary Disease Cohort. Npj Prim Care Respir Med. 2017;27(1):46. doi:10.1038/s41533-0170046-6

25. Rockenschaub P, Jhass A, Freemantle N, et al. Opportunities to reduce antibiotic prescribing for patients with COPD in primary care: a cohort study using electronic health records from the Clinical Practice Research Datalink (CPRD). J Antimicrob Chemother. 2020;75(1):243-251. doi:10.1093/ $\mathrm{jac} / \mathrm{dkz} 411$

26. Meguro M, Barley EA, Spencer S, Jones PW. Development and validation of an improved, COPD-specific version of the St. George respiratory questionnaire. Chest. 2007;132(2):456-463. doi:10.1378/chest.06-0702.

27. Guyatt GH, Berman LB, Townsend M, Pugsley SO, Chambers LW. A measure of quality of life for clinical trials in chronic lung disease. Thorax. 1987;42(10):773-778. doi:10.1136/thx.42.10.773

28. Aaron SD, Donaldson GC, Whitmore GA, Hurst JR, Ramsay T, Wedzicha JA. Time course and pattern of COPD exacerbation onset. Thorax. 2012;67(3):238LP- 243. doi:10.1136/thoraxjnl-2011-200768.

29. Meeraus WH, Mullerova H, El Baou C, Fahey M, Hessel EM, Fahy WA. Predicting re-exacerbation timing and understanding prolonged exacerbations: an analysis of patients with COPD in the ECLIPSE cohort. Int J Chron Obstruct Pulmon Dis. 2021;16:225-244. doi:10.2147/ COPD.S279315

30. Seemungal TA, Donaldson GC, Bhowmik A, Jeffries DJ, Wedzicha JA. Time course and recovery of exacerbations in patients with chronic obstructive pulmonary disease. Am J Respir Crit Care Med. 2000;161(5):1608-1613. doi:10.1164/ajrccm.161.5.9908022 
31. Melbye H, Straume B, Aasebø U, Dale K. Diagnosis of pneumonia in adults in general practice. Relative importance of typical symptoms and abnormal chest signs evaluated against a radiographic reference standard. Scand J Prim Health Care. 1992;10(3):226-233. doi:10.3109/ 02813439209014066

32. Francis NA, Melbye H, Kelly MJ, et al. Variation in family physicians' recording of auscultation abnormalities in patients with acute cough is not explained by case mix. A study from 12 European networks. Eur J Gen Pract. 2013;19(2):77-84. doi:10.3109/13814788.2012.733690

33. El-Shafey BI, El-Deib AE. Effect of weight reduction on obese patients with COPD and bronchial asthma. Egypt J Chest Dis Tuberc. 2015;64 (4):773-778. doi:10.1016/j.ejcdt.2015.06.007.

34. McDonald V, Gibson P, Scott H, et al. Obesity in COPD, how should it be managed? - The effect of weight loss and resistance training in obese COPD patients. Eur Respir J. 2014:44(Suppl 58); P3035.

35. Kim V, Aaron SD. What is a COPD exacerbation? Current definitions, pitfalls, challenges and opportunities for improvement. Eur Respir J. 2018;52(5):1801261. doi:10.1183/13993003.01261-2018

International Journal of Chronic Obstructive Pulmonary Disease

\section{Publish your work in this journal}

The International Journal of COPD is an international, peer-reviewed journal of therapeutics and pharmacology focusing on concise rapid reporting of clinical studies and reviews in COPD. Special focus is given to the pathophysiological processes underlying the disease, intervention programs, patient focused education, and self management protocols. This journal is indexed on PubMed Central, MedLine and CAS. The manuscript management system is completely online and includes a very quick and fair peer-review system, which is all easy to use. Visit http://www. dovepress.com/testimonials.php to read real quotes from published authors.

Submit your manuscript here: https://www.dovepress.com/international-journal-of-chronic-obstructive-pulmonary-disease-journal 